\title{
Clinicopathological and Prognostic Features of Hepatitis B Virus-associated Diffuse Large B-cell Lymphoma: A Single-Center Retrospective Study in China
}

\section{Dao-guang Chen}

fu jian yi ke da xue: Fujian Medical University

\section{Gang Chen}

fu jian yi ke da xue: Fujian Medical University

\section{Chang Wang}

fu jian yi ke da xue: Fujian Medical University

\section{Long-feng Ke}

fu jian yi ke da xue: Fujian Medical University

Hui Wu

fu jian yi ke da xue: Fujian Medical University

Hong-ming He

fu jian yi ke da xue: Fujian Medical University

Yu Yang

fu jian yi ke da xue: Fujian Medical University

Yanping Chen ( $\nabla$ kelf2006@126.com )

fu jian yi ke da xue: Fujian Medical University

\section{Research Article}

Keywords: prognosis, hepatitis B virus, diffuse large B-cell lymphoma, R-CHOP

Posted Date: February 17th, 2021

DOI: https://doi.org/10.21203/rs.3.rs-202316/v1

License: (c) (i) This work is licensed under a Creative Commons Attribution 4.0 International License. Read Full License

Version of Record: A version of this preprint was published at Infectious Agents and Cancer on August 17th 2021 See the nubliched versinn at httrs://doi.org/10.1186/s13027-021-00396-X. 


\section{Abstract}

The main aim of our study was to retrospectively investigate the clinicopathological characteristics and prognosis factors of DLBCL patients with HBV infection in China.

We collected 420 patients with DLBCL who were originally diagnosed and treated at Fujian Cancer Hospital, China. In our study, 127 (30.2\%) patients were HBsAg-positive. HBsAg-positive DLBCL displayed a younger median onset age (50 vs. 54 years, $P=0.002)$, more frequent involvement of the spleen $(19.7 \%$ vs. $6.1 \%, P<0.001)$, less frequent involvement of the small and large intestine $(2.3 \%$ vs $11.2 \%, P=0.003)$, more advanced disease (stage III/IV: $56.7 \%$ vs. $45.1 \%, P=0.028)$, and lower expression rate of MYC $(49.1 \%$ vs. $66.7 \%, P=0.026)$. The median follow-up time was 61.9 months. Univariate analysis showed that there was no significant difference in overall survival (OS) between HBsAg-negative and -positive DLBCL $(P=0.577)$. In the HBsAg-positive DLBCL subgroup, age older than 60 years, advanced disease, elevated lactate dehydrogenase (LDH), spleen involvement, B symptoms (fever, night sweats, weight loss), and double expressers of MYC and BCL2 had a significantly worse outcome, and patients treated with RCHOP (rituximab plus cyclophosphamide, doxorubicin, vincristine, and prednisone) had a better prognosis. Multivariate analysis further confirmed that spleen involvement and rituximab use were independent prognostic factors in HBsAg-positive DLBCL patients. Our study indicates that HBsAgpositive DLBCL has unique clinicopathological features and independent prognostic factors. Moreover, HBV infection does not appear to affect the prognosis of DLBCL patients, and the use of rituximab significantly improves OS in HBsAg-positive DLBCL patients.

\section{Introduction}

Diffuse large B-cell lymphoma (DLBCL), the most frequent type of B-cell lymphoma, constitutes $25 \%$ $35 \%$ of adult non-Hodgkin lymphoma cases in developed countries and a higher percentage in developing countries. ${ }^{1-2}$ This entity encompasses distinct morphological, molecular, and clinicopathological subgroups. At present, $\mathrm{CHOP} / \mathrm{CHOP}$-like (cyclophosphamide, doxorubicin, vincristine, and prednisolone) or R-CHOP (CHOP plus rituximab) regimens are the standard first-line therapy for DLBCL patients. ${ }^{3-5}$ However, there are certain disadvantages to first-line chemotherapy, including hepatitis $B$ virus (HBV) reactivation in response to MabThera and activated or aggravated HBV infection status. ${ }^{6-8}$ Therefore, the prophylaxis and management of this complication has become a major issue in the management of DLBCL patients with chronic HBV infection. The data indicate that HBsAg positivity is an unfavorable prognostic factor for patients treated with MabThera, ${ }^{9-11}$ but whether a patient's prognosis is influenced by the presence of an HBV infection has been little reported.

At present, HBV infection remains a significant public health problem. Over 2 billion people have evidence of HBV infection, and approximately 350 million are chronic carriers worldwide. ${ }^{12}$ China is an endemic area for HBV infection with a HBsAg positivity rate of $7.18 \%$ in the general population and around 93 million chronically infected patients. ${ }^{13} \mathrm{HBV}$ is a hepatotrophic and lymphotropic virus, and HBV infection

Loading [MathJax]/jax/output/CommonHTML/jax.js bute to the development of lymphoproliferative disorders. ${ }^{14}$ 
Many studies have found a higher prevalence of HBV infection in non-Hodgkin's lymphoma (NHL) patients, especially those with DLBCL, than in the general population. ${ }^{15-23}$ While the epidemiological association between HBV infection and DLBCL is established, few articles have systematically investigated the clinicopathological characteristics and adverse prognostic factors of DLBCL patients with HBV infection. Some researchers reported that the survival of DLBCL patients with HBV infection is poor compared with DLBCL patients without HBV infection, ${ }^{24-28}$ while others found that, in both HBsAgpositive and -negative DLBCL patients, the median overall survival (OS) is similar. ${ }^{29-30}$

Because HBV infection is very common in China, it is important to understand its impact on clinicopathological characteristics and outcomes among DLBCL patients receiving treatment. Therefore, the main aim of our study was to retrospectively investigate the clinicopathological characteristics and prognosis of DLBCL patients with HBV infection and compare them with those of patients without HBV infection in a cohort of 420 patients with DLBCL.

\section{Materials And Methods}

\section{Patients and tissue collection}

This retrospective study was performed on 420 patients with DLBCL who were originally diagnosed and treated at Fujian Cancer Hospital, China, from March 2011 to February 2018. Cases of secondary DLBCL transformed from low grade B-cell lymphoma, de novo CD5-positive DLBCL, and specific entities (such as EBV-positive diffuse large B-cell lymphoma, NOS ) were excluded from the selection. All cases were reviewed by two hematopathologists to confirm the histological diagnosis according to the criteria of the 2017 World Health Organization (WHO) classification of tumors of hematopoietic and lymphoid tissues. ${ }^{2}$ The staging was determined according to the Ann Arbor Staging Criteria. Response to treatment was evaluated according to the standard response criteria (physical examination, CT scan, and bone marrow biopsy), and imaging studies were performed after every two cycles of chemotherapy. All patients received a standard $\mathrm{CHOP}$ (cyclophosphamide, doxorubicin, vincristine, and prednisone) regimen or rituximab plus $\mathrm{CHOP}$ (R-CHOP) as the first-line treatment. After chemotherapy, patients with residual disease or bulky disease were routinely given regional radiation therapy (RT) to the involved sites. HBsAgpositive patients routinely received lamivudine or entecavir prophylactic treatment, starting from the beginning of chemotherapy and stopping one year after its completion. When the HBV deoxyribonucleic acid (DNA) in the serum of HBsAg-positive patients was below $2 \times 10^{3}$ copies $/ \mathrm{ml}$, rituximab was commenced. Clinical, laboratory, and follow-up data were obtained from patient medical records and charts. This study was carried out in accordance with the Declaration of Helsinki and written informed consent was obtained from the patients or their legal guardians. The study protocol was approved by the institutional review boards of Fujian Cancer Hospital.

\section{Histology and immunohistochemical analysis}


Biopsy specimens were fixed in 10\% formalin and embedded in paraffin after routine histological tissue processing. Three to four micrometer-thick formalin-fixed paraffin-embedded tissue (FFPE) sections were stained with hematoxylin-eosin (HE) for microscopic examination. All immunohistochemistry assays were performed on diagnosed patient tissues available in the form of FFPE tissue blocks using VentanaBenchmark XT automated instruments at the Department of Pathology. Immunostaining on paraffin sections was performed for CD20, CD21, CD3, Ki-67, CD10, BCL-6, IRF4/MUM-1, BCL-2, MYC, cyclin D1, CD5, CD30, and p53 (all clones from Maixin Biotech Co., Ltd., Fuzhou, China). Conditions for individual immunohistochemistry assays including antigen retrieval and antibody dilutions varied according to the antibody used and were determined by standard optimization and validation procedures. Positive and negative staining controls were included as appropriate. CD10, BCL6, and IRF4/MUM1 were each considered positive if $\geq 30 \%$ of the tumor cells were positively stained2. According to the 2016 revised WHO guidelines 2 , BCL2 was considered positive if $\geq 50 \%$ of the tumor cells were positive, and MYC was considered positive if $\geq 40 \%$ of the tumor cell nuclei were positive. To define elevated p53 protein expression, a cut-off was set at $50 \%$ positively staining cells as proposed by Xu-Monette and colleagues. 31

\section{HBV detection}

Routine screening for viral markers including HBsAg, hepatitis-B surface antibody (HBsAb), hepatitis-B e antigen ( $\mathrm{HBeAg}$ ), hepatitis-B e antibody (HBeAb), and hepatitis-B core antibody (HBcAb) was performed by chemiluminescence immunoassay on an Architect-i2000 instrument (Abbott Laboratories). Real-time quantitative polymerase chain reaction was used to determine the HBV DNA copy number before chemotherapy if HBsAg was positive.

\section{In situ hybridisation}

Epstein-Barr virus (EBV) detection by in situ hybridization was performed in all cases using FITC-labeled oligonucleotide probe supplied by Ventana to detect EBV-encoded RNA (EBER). In situ hybridization for EBER was conducted on FFPE sections on an automated stainer (Ventana-Benchmark XT) according to the manufacturer's instructions. The visualization was achieved using the ISH iView system with alkaline phosphatase and NT/BCIP substrate, with fast red as a contrast. EBV-positive nasopharyngeal carcinoma was chosen as the positive control.

\section{Statistical analysis}

SPSS software (version 20.0, IBM, Armonk, NY, USA) was used for all statistical analyses. The patient's characteristics were compared across different subgroups using Pearson's chi-squared test or Fisher's exact test. OS was determined from the date of diagnosis to the date of death or the last follow-up. 
using the log-rank test. Multivariate analysis was conducted with the Cox proportional hazards model, which included the variables that were significant in the univariate analysis. A P-value of $<0.05$ was considered statistically significant.

\section{Results}

\section{Baseline clinicopathological characteristics in all patients with DLBCL}

The study group included 237 males and 183 females with a male-to-female ratio of 1.3:1. The age of onset ranged from 16 to 86 years, with a median age of 53 years and an average age of 51.6 years. Among these patients, 119 patients (28.3\%) were older than 60 years. There were 66 (15.7\%), 150 (35.7\%), 78 (18.6\%), and 126 (30.0\%) patients with Ann Arbor stage I, II, III, and IV disease, respectively. There were 335 (79.8\%) and 85 (20.2\%) patients with low International Prognostic Index (IPI) and high IPI, respectively. B symptoms, bulky mass $(\geq 7.5 \mathrm{~cm})$, elevated lactate dehydrogenase (LDH), and extra-nodal sites $\geq 2$ were identified in 43 (10.2\%), 74 (17.6\%), 194 (46.2\%), and 71 (16.9\%) patients, respectively. The follow-up time ranged from 58.0 to 65.8 months (median, 61.9 months). One hundred and forty-four of the 420 patients died of the disease. The 3 - and 5-year OS rates were $71.3 \%$ and $64.9 \%$, respectively.

All cases were strongly positive for CD20 and negative for CD3, CD5, and cyclin- D1. The germinal center B-cell (GCB) and non-GCB subtypes of DLBCL were classified based on immunohistochemical staining of CD10, BCL-6, and MUM-1 by Hans' algorithm. Among 420 cases, 266 (63.3\%) cases demonstrated a nonGCB immunophenotype, whereas 154 (36.7\%) cases demonstrated a GCB immunophenotype. The ratio of non-GCB to GCB phenotype was $1.7: 1$. The Ki-67 proliferation index was generally high, and was usually much more than $40 \%$, with $>60 \%$ in 331 (78.8\%) cases. There were $271 / 360(75.3 \%)$ and 106/174 (60.9\%) cases that tested positive for BCL-2 and MYC, respectively, and 79/172 (45.9\%) cases were positive for both BCL2 and MYC. Coexpression of these two proteins (so-called double expressers) was more frequent in the non-GCB subtype. There were $27 / 114$ (23.7\%) cases that tested positive for p53. CD30 was weakly and focally expressed in some cases. All cases were negative for EBER.

\section{Clinicopathological features of HBsAg-positive DLBCL patients}

The clinicopathological characteristics of HBsAg-positive and -negative patients are shown in Table 1 and Table 2. One hundred and twenty-seven patients were HBsAg-positive (127/420, 30.2\%) and 293 (69.8\%) were HBsAg-negative. Compared with patients in the HBsAg-negative group, patients in the HBsAg-positive group were of a younger age with a median onset age of 50 years (range, 18-82) vs 54 years (range, 16-86) in the HBsAg-negative group ( $P=0.002$ ). In the HBsAg-positive group, fewer patients were over 60 years (17.3\% vs. $33.1 \%, P<0.001$, Figure 2$)$. Furthermore, DLBCL in the HBsAg-positive group Loading [MathJax]/jax/output/CommonHTML/jax.js bleen (19.7\% vs. 6.1\%, $\mathrm{P}<0.001)$, more advanced disease 
(stage III/IV: $56.7 \%$ vs. $45.1 \%, P=0.028)$, less frequent involvement of the small and large intestine $(2.3 \%$ vs. $11.2 \%, P=0.003)$, and lower expression rate of MYC ( $49.1 \%$ vs. $66.7 \%, P=0.026)$. Eighty cases $(80 / 127$, $63.0 \%)$ in the HBsAg-positive group compared with $186(186 / 293,63.4 \%)$ in the HBsAg-negative group were classified as being of the non-GCB subtype of DLBCL. There was no significant difference in the percentage of non-GCB patients between these two groups $(P=0.924)$. Furthermore, there was no significant difference in sex, bulky mass, performance status, B symptoms, elevated LDH, extra-nodal sites $\geq 2$, high IPI, use of rituximab, Ki-67 proliferation index, expression of BCL2, p53 expression, and coexpression of BCL2 and MYC between the HBsAg-positive and -negative groups. Treatment response in patients with $\mathrm{R}-\mathrm{CHOP} / \mathrm{CHOP}$ regimen between $\mathrm{HBsAg}$-positive and -negative groups (Table S1, S2). Furthermore, in the HBsAg-positive DLBCL group, though there was no significant statistical difference in complete response between the $\mathrm{R}-\mathrm{CHOP}$ and $\mathrm{CHOP}$ groups, complete response in the R-CHOP group was better than that in the CHOP group with a higher rate of complete response $(70.0 \%$ vs $54.5 \%, P=0.082$, Table 3). Additionally, for HBsAg-positive DLBCL patients, remission rate did not differ between the GCB and non-GCB subtypes ( $P=0.252$, Table 4$)$.

\section{Survival analysis in HBsAg-positive DLBCL patients}

The median follow-up time was 66.9 months (range, 60.7-73.1) for the HBsAg-positive group and 63.9 (range, 60.1-67.7) months for the HBsAg-negative group. Patients in the HBsAg-positive group did not show significantly worse OS than those in the HBsAg-negative group with a 3 -year OS of $73.6 \%$ vs $70.2 \%$ and a 5 -year OS of $63.0 \%$ vs $65.6 \%(P=0.577$, Figure $3 A)$. However, there was a tendency that HBV infection affected the prognosis of DLBCL patients under 60 years of age (Figure S1). There was a better outcome regarding $O S$ in patients under 60 years of age in the HBsAg-positive group ( $P=0.0377$, Figure $3 B$ ). In the HBsAg-positive DLBCL subgroup, patients with advanced disease, elevated LDH, spleen involvement, or $B$ symptoms had a significantly worse outcome $(P=0.0002, P=0.0487, P=0.034$, and $P=0.0003$, respectively, Figure 3C, 3D, 3E and 3F). One hundred and twenty of the $127 \mathrm{HBsAg}$-positive patients had HBeAg and HBV DNA loads. For the $120 \mathrm{HBsAg-positive} \mathrm{DLBCL}$ patients, the survival analysis showed that OS did not differ between HBV DNA- and HBeAg-positive and HBV DNA- and HBeAg-negative patients $(P=0.536$ and $P=0.534$, respectively). In the HBsAg-positive DLBCL patients, coexpression of BCL2 and MYC had a significantly worse outcome ( $P=0.048$, Figure $3 G)$. However, high expression of Ki-67 proliferation index, $B C L 2, M Y C$, and p53 did not affect prognosis $(P=0.676, P=0.074$, $P=0.167$, and $P=0.875$, respectively). For HBsAg-positive DLBCL patients, OS did not differ between the GCB and non-GCB subtypes ( $P=0.124)$. In our study, 203 of the $420(203 / 420,48.1 \%)$ patients were treated with $\mathrm{R}-\mathrm{CHOP}$ and the remainder were treated with $\mathrm{CHOP}$. The survival analysis revealed that patients treated with R-CHOP had a better prognosis $(\mathrm{P}<0.001$, Figure $3 \mathrm{H})$. Correspondingly, there was better OS in the HBsAg-positive DLBCL patients treated with R-CHOP compared with those that received CHOP $(P=0.0152$, Figure $3 \mathrm{I})$. The poor prognostic factors between HBsAg-positive and -negative groups were similar except B symptoms (Table 5 and Figure S2). Multivariate analysis further confirmed that spleen involvement and use of rituximab were independent prognostic factors in HBsAg-positive DLBCL

Loading [MathJax]/jax/output/CommonHTML/jax.js 0.007 , and HR 0.294, 95\% Cl 0.102-0.843, $\mathrm{P}=0.023$, 
respectively, Table 6), while clinical staging and use of rituximab were independent prognostic factors in HBsAg-negative DLBCL patients (Table S3).

\section{Discussion}

HBV infection is endemic in some parts of Asia, Africa, and South America, and remains a significant public health problem in these areas. To our knowledge, this is one of the few studies to examine whether the presence of HBV infection affected the clinical characteristics and outcomes in patients with DLBCL, our study included $127 \mathrm{HBsAg}$-positive patients, which was the largest number of patients in all studies of this disease. In our study, HBV prevalence in DLBCL patients was approximately $30.2 \%$, which was similar or higher than the $13.3 \%-30.9 \%$ observed in previous studies from China, Singapore, and another Asian country. 9,11,24, 32-34 These results suggested that in HBV-prevalent regions, a certain percentage of DLBCL patients are chronically infected with HBV.

At present, many epidemiological studies, case-control studies, and meta-analyses have shown that HBV infection may increase the incidence of several types of B-cell lymphoma, especially DLBCL. While the epidemiological association between HBV infection and DLBCL is established, the etiopathological role of HBV in lymphomagenesis remains largely unknown. Ren and colleagues ${ }^{35}$ performed the first comprehensive genomic and transcriptomic study on DLBCL samples from patients with HBV infection and identified distinct molecular features of these tumors, suggesting a direct link between HBV infection and B-cell malignancy. They found an enhanced rate of mutagenesis and a distinct set of mutational targets in HBV-associated DLBCL genomes, which could be partially explained by the activities of APOBEC and activation-induced cytidine deaminase. Moreover, the HBV-associated gene expression signature is impacted by the enrichment of genes regulated by BCL6, FOXO1, and ZFP36L1. They also showed that an antigen-independent mechanism is favored in HBV-related lymphomagenesis.

In our study, we further found HBsAg-positive DLBCL patients showed unique clinical features, including an earlier disease onset age, much more common involvement of the spleen, less frequent involvement of the small and large intestine, and more advanced disease. An earlier disease onset age in HBsAg-positive patients was reported in studies conducted in Korea ${ }^{22}$ and China. ${ }^{11,24,29,32,35}$ More advanced stage and frequent involvement of the spleen in HBsAg-positive DLBCL patients were also reported by some groups, $24,29,35$ but not by others. ${ }^{9,11,30}$ This discrepancy might be ascribed to the small sample sizes ${ }^{30}$ and different prevalence of HBV infection. Interestingly, we found that HBsAg-positive DLBCL patients displayed less frequent involvement of the small and large intestine, which was not reported by previous studies.

In the era of DLBCL sub-classification, with cell-of-origin (COO) algorithms having entered clinical practice and being included in the 2016 revision of the WHO classification, we investigated the proportion of the non-GCB subtype in HBsAg-positive and -negative DLBCL patients, and the treatment response and outcome between the GCB and non-GCB subgroups in HBsAg-positive DLBCL patients. We identified 63\% 
groups, which suggests HBV infection might not participate in certain downstream molecular pathways, leading to GCB and non-GCB subgroup involvement. In addition, for HBsAg-positive DLBCL patients, the OS and remission rate did not differ between the GCB and non-GCB subtypes. Thus, our study did not find a significant representation of the $\mathrm{COO}$ subtype in $\mathrm{HBsAg-positive} \mathrm{DLBCL}$, which may have an influence on the prognosis. However, due to the small sample size and the lack of the gold standard $\mathrm{COO}$ classification by gene expression profile, further studies on the $\mathrm{COO}$ in HBsAg-positive patients are required.

MYC protein expression has been shown to be a poor prognostic factor in the rituximab era, which is compounded by BCL2 co-expression (double-positive or double-expressor lymphomas). Some study groups have reported that a high proliferation index (>60\% to $80 \%)$ is associated with poor prognosis. Several studies have shown positive immunoreactivity for $\mathrm{p} 53$ protein to be a poor prognostic indicator in DLBCL. To date, there have been no related reports in HBsAg-positive DLBCL patients. Our study showed that coexpression of BCL2 and MYC had a significantly worse outcome in HBsAg-positive DLBCL patients, while high expression of Ki-67 proliferation index, BCL2, MYC, and p53 did not affect prognosis in HBsAg-positive DLBCL patients. This result suggests that the OS of HBsAg-positive DLBCL patients could be improved by first-line chemotherapy combined with new targeted drugs such as ibrutinib.

Additionally, our study showed that there was a significant difference in the expression of MYC between the HBsAg-positive and -negative group. The expression rate of MYC in the HBsAg-positive group was significantly lower than that in the HBsAg-negative group. In contrast, Huang and colleagues ${ }^{36}$ reported the reverse finding, showing that $\mathrm{HBx}$ expression was significantly associated with high-level expression of MYC. Liu and colleagues ${ }^{26}$ found that the rate of MYC and BCL2 gene rearrangements in the HBVinfected group was significantly higher than that in the HBV-free group. It is likely that HBx antigen may contribute to the MYC signaling pathway and mediate lymphomagenesis in HBV+ patients. However, acording to Ren and colleagues's report ${ }^{35}$, the HBV-associated gene expression signature is impacted by the enrichment of genes regulated by BCL6, FOX01, and ZFP36L1. So further multicenter clinical studies on larger cohorts of HBV-associated DLBCL are required for the identification and validation of candidate driver genes and will shed light on the complex mechanism underlying HBV infection and B-cell lymphomagenesis.

Most importantly, our study showed that there was no statistically significant difference in OS between HBsAg-positive and -negative patients. We also found that there was better OS in HBsAg-positive DLBCL patients treated with R-CHOP compared with those who received $\mathrm{CHOP}$. However, our results were inconsistent with the findings of previous studies. ${ }^{24-28}$ We believe that there are two main reasons for this anomaly. On one hand, the poor prognostic factors between HBsAg-positive and -negative groups were similar except B symptoms. Furthermore, in our study, there was no difference in the use of rituximab and treatment response with $\mathrm{R}-\mathrm{CHOP}$ regimen between $\mathrm{HBsAg-positive} \mathrm{and} \mathrm{-negative} \mathrm{DLBCL}$ patients, which contributed to the similar prognosis of these two groups. On the other hand, although HBsAg-positive DLBCL patients had a higher risk of developing hepatic dysfunction and HBV reactivation Loading [MathJax]/jax/output/CommonHTML/jax.js on higher than grade 2 and HBV reactivation both occurred in 
only $6.2 \%$ of HBsAg-positive DLBCL patients. Fatal hepatitis due to HBV reactivation in patients using rituximab has been reported. However, prophylactic antiviral therapy reduces the occurrence of potentially serious hepatic complications, allowing more patients to continue chemotherapy uninterrupted, and resulting in a trend towards improved OS. In our study, HBsAg-positive patients were routinely administered lamivudine or entecavir prophylactic treatment, starting from the beginning of chemotherapy and stopping one year after the completion of chemotherapy. Only two HBsAg-positive patients developed severe liver failure. There was no statistically significant difference in OS between HBsAg-positive and -negative patients. A study by Wang et al. also showed that there was no statistically significant difference in OS between HBsAg-positive and -negative patients, while the OS of HBsAgpositive patients with hepatic dysfunction during chemotherapy was significantly shorter than that of patients without liver dysfunction, ${ }^{29}$ suggesting that hepatic dysfunction is a poor prognostic factor and contributes to poor outcome.

\section{Conclusion}

The current study showed that HBsAg-positive DLBCL has unique clinicopathological features and poor prognostic factors. However, HBV infection did not appear to affect the prognosis of DLBCL patients. HBsAg-positive DLBCL patients may benefit from prophylactic antiviral treatment and the use of rituximab significantly improved OS in HBsAg-positive DLBCL patients.

\section{Declarations}

\section{Funding}

This study was funded by the Natural Science Foundation of Fujian Province (grant number 2018J01277), Joint Funds for the Innovation of Science and Technology, Fujian province (grant number 2017Y9081) and Science and Technology Program of Fujian Province, China (grant number 2018Y2003).

\section{Conflict of Interest}

All authors declare that they have no conflict of interest.

\section{Ethical approval}

This study was carried out in accordance with the Declaration of Helsinki and written informed consent was obtained from the patients or their legal guardians. The study protocol was approved by the institutional review boards of Fujian Cancer Hospital (ethics number 2017-084-01). This article does not contain any studies with human participants or animals performed by any of the authors.

\section{Acknowledgments}

We thank H. Nikki March, PhD, from Liwen Bianji, Edanz Editing China (www.liwenbianji.cn/ac), for Loading [MathJax]/jax/output/CommonHTML/jax.js huscript. 


\section{References}

1. Swerdlow SH, Campo E, Pileri SA, et al. The 2016 revision of the World Health Organization classification of lymphoid neoplasms. Blood. 2016; 127: 2375-2390.

2. Swerdlow SH,Campo E, Harris NL,et al. WHO classification of tumours of haematopoietic and lymophoid Tissues. Lyon: IARC Press. 2017;pp. 291-298.

3. Pfreundschuh $M$, Kuhnt $E$, Trumper $L$, et al. Chop-like chemotherapy with or without rituximab in young patients with good-prognosis DLBCL: 6-year results of an open-label randomized study of the MinT Group. Lancet oncol .2011;12 (11):1013-1022.

4. Coiffier B, Thieblemont C, Van Den Neste E, et al. Long-term outcome of patients in the LNH-98.5 trial, the first randomized study comparing rituximab-CHOP to standard $\mathrm{CHOP}$ chemotherapy in DLBCL patients: a study by the GROUPE DEtudesdesLymphomesdelAdulte. Blood.2010;116 (12):20402045.

5. Coiffier B. Rituximab in combination with $\mathrm{CHOP}$ improves survival in elderly atients with aggressive non-Hodgkin's lymphoma. Semin Oncol. 2002; 29: 18-22.

6. Hsu C, Tsou HH, Lin SJ, et al. Chemotherapy-induced hepatitis B reactivation in lymphoma patients with resolved HBV infection: a prospective study. Hepatology. 2014; 59(6):2092-2100.

7. Niitsu N, Hagiwara $Y$, Tanae $K$, et al. Prospective analysis of hepatitis $B$ virus reactivation in patients with diffuse large B-cell lymphoma after rituximab combination chemotherapy. J Clin Oncol. 2010; 28(34):5097-5100.

8. Fukushima N, Mizuta T, Tanaka M, et al. Retrospective and prospective studies of hepatitis $B$ virus reactivation in malignant lymphoma with occult HBV carrier. Ann Oncol. 2009; 20 (12):2013-2017.

9. Wei Z, Zou S, Li F, et al. HBsAg is an independent prognostic factor in diffuse large B cell lymphoma patients in rituximab era: result from a muticenter retrospective a nalysis in China. Med Oncol.2014; 31(3):845-126.

10. Guo W, Zhang W, Liu C, et al. Clinical Analysis of the HBV Infection Status of 135 Patients with Diffuse Large B Cell Lymphoma Treated with R-CHOP or CHOP/CHOP-Like Chemotherapy. PLOS ONE. 2015; 10(6): e0129064.

11. Xie W, Zhou D, Hu K, et al. Clinical analysis and prognostic significance of hepatitis B virus infections for diffuse large B-cell lymphoma with or without rituximab therapy. Exp Ther Med. 2013; 6(1):109114.

12. Yu M, Lin C, Liu C, et al. Influence of Metabolic Risk Factors on Risk of Hepatocellular Carcinoma and Liver-related Death in Men with Chronic Hepatitis B: A Large Cohort Study. Gastroenterology. 2017; 153(4):1006-1017.

13. Liang X, Bi S, Yang W, et al. Reprint of: Epidemiological serosurvey of Hepatitis B in China-declining HBV prevalence due to Hepatitis B vaccination. 2013; 31: J21-J28.

14. Coluccio C, Begini P, Marzano A, etal. Hepatitis B in patients with hematological disease: an update. 
15. Chen M, Hsiao L T, Chiou T J, et al. High prevalence of occult hepatitis $B$ virus infection in patients with B cell non-Hodgkin's lymphoma. Ann Hematol. 2008; 87(6):475-480.

16. Nath A, Agarwal R, Malhotra $P$, et al. Prevalence of hepatitis $B$ virus infection in non-Hodgkin lymphoma: a systematic review and meta-analysis. Intern Med J. 2010; 40(9):633-641.

17. Becker N, Schnitzler P, Boffetta $P$, et al. Hepatitis $B$ virus infection and risk of lymphoma: results of a serological analysis within the European case-control study Epilymph. J Cancer Res Clin Oncol. 2012; 138(12):1993-2001.

18. Kang $\mathrm{J}$, Cho $\mathrm{J} \mathrm{H}$, Suh $\mathrm{C} \mathrm{W}$, et al. High prevalence of hepatitis $B$ and hepatitis $\mathrm{C}$ virus infections in Korean patients with hematopoietic malignancies. Ann Hematol .2011; 90(2):159-164.

19. Marcucci F, Mele A. Hepatitis viruses and NHL: epidemiology, mechanisms of tumorigenesis, and therapeutic opportunities. Blood. 2011; 117(6):1792-1798.

20. Dalia S, Chavez J, Castillo J J, et al. Hepatitis B infection increases the risk of non-Hodgkin lymphoma: A meta-analysis of observational studies. Leuk Res. 2013; 37(9):1107-1115.

21. Taborelli M, Polesel J, Maurizio Montella. Hepatitis B and C viruses and risk of non-Hodgkin lymphoma: a case-control study in Italy. Infec Agents Cancer. 2016; 11(1):27-33.

22. Kim J H, Bang $Y$ J, Park B J, et al. Hepatitis B Virus Infection and B-Cell Non-Hodgkin's Lymphoma in a Hepatitis B Endemic Area: A Case-control Study. JPN J CANCER RES. 2002; 93(5):471-477.

23. Wang C, Xia B, Ning Q, et al. High prevalence of hepatitis B virus infection in patients with aggressive B cell non-Hodgkin's lymphoma in China. Ann Hematol.2018; 97(3) :453-457.

24. Deng $L$, Song $Y$, Young $K \mathrm{H}$, et al. Hepatitis $B$ virus-associated diffuse large B-cell lymphoma: Unique clinical features, poor outcome, and hepatitis B surface antigen-driven origin. Oncotarget. 2015; 6(28):25061-25075.

25. Rong $X$, Wang $\mathrm{H}, \mathrm{Ma} \mathrm{J}$, et al. Chronic hepatitis $B$ virus infection is associated with a poorer prognosis in diffuse large B-cell lymphoma: a meta-analysis and systemic review. J Cancer. 2019; 10(15): 3450-3458.

26. Liu Z, Li S, Guo W, et al. MYC Gene Rearrangements Are Closely Associated with Poor Survival of Diffuse Large B Cell Lymphoma with Hepatitis B Virus Infection. BioMed Res. Int 2017; (4):1-7.

27. Al-Mansour M M, Alghamdi S A, Alsubaie M A, et al. Negative effect of hepatitis in overall and progression-free survival among patients with diffuse large B-cell lymphoma. Infect Agents Cancer. 2018; 13(1):18.

28. Liu Z, Li S, Liu Y, et al. PD1 is highly expressed in diffuse large B-cell lymphoma with hepatitis B virus infection. PLOS ONE. 2017; 12(6): e0180390.

29. Wang $F, X u R H$, Luo H Y, et al. Clinical and prognostic analysis of hepatitis $B$ virus infection in diffuse large B-cell lymphoma. BMC Cancer. 2008; 8(1):115-126.

30. Law M.F, Lai H.K, Chan H.N, et al. The impact of hepatitis B virus (HBV) infection on clinical outcomes of patients with diffuse large B-cell lymphoma. Eur J Cancer Care. 2015; 24(1):117-124. 
31. Xu-Monette ZY, Wu L, Visco C, et al. Mutational profile and prognostic significance of TP53 in diffuse large B-cell lymphoma patients treated with R-CHOP: report from an International DLBCL RituximabCHOP Consortium Program Study. Blood. 2012; 120:3986-3996.

32. Wang F, Xu RH, Han B, et al. High incidence of hepatitis B virus infection in B-cell subtype nonHodgkin lymphoma compared with other cancers. Cancer. 2007; 109:1360-1364.

33. Zhang M, Wu G, Sun Z, et al. An analysis of HBV infection in Non-hodgkin lymphoma patients. Chin J Basic Clin Oncology. 2006; 19:467-468.

34. $\mathrm{He} \mathrm{H}$, Zhai $M$, Zhang $D$, et al. Clinical significance of detecting serum label of hepatitis $B$ virus in $\mathrm{NHL}$ patients. J Chin Clin Med. 2003; 4:8-10.

35. Ren W, Ye X, Su H, et al. Genetic landscape of hepatitis B virus-associated diffuse large B-cell lymphoma. Blood. 2018; 131(24):2670-2681.

36. Huang X, Ken H. Young, Guo W, et al. Identification of Hepatitis B virus etiologic antigens, HBx and Pre-S2, in Diffuse Large B-cell Lymphoma. J Viral Hepatitis. 2020.

\section{Tables}

Table 1: Clinical characteristics of HBsAg-positive and negative patients 


\begin{tabular}{|c|c|c|c|}
\hline clinical factor & $\begin{array}{l}\text { HBsAg-positive } \\
\text { patients(N=127 ) n(\%) }\end{array}$ & $\begin{array}{l}\text { HBsAg-negative } \\
\text { patients(N=293) } n(\%)\end{array}$ & $\begin{array}{l}P \\
\text { value }\end{array}$ \\
\hline Age $₫ 60$ & $22(17.3)$ & 97(33.1) & 0.001 \\
\hline Median onset age & 50 & 54 & 0.002 \\
\hline Gender, male & $79(62.2)$ & 158(53.9) & 0.116 \\
\hline Bulky mass $(\geq 7.5 \mathrm{~cm})$ & $22(17.3)$ & $52(17.7)$ & 0.916 \\
\hline \multicolumn{4}{|l|}{ Special sites involvement } \\
\hline Liver & $6(4.7)$ & 10(3.4) & 0.519 \\
\hline Spleen & $28 \rrbracket 22.0 \rrbracket$ & $19 \llbracket 6.5 \rrbracket$ & 0.001 \\
\hline Stomach & 11(8.6) & $34(11.6)$ & 0.371 \\
\hline Intestinal & $3(2.3)$ & $33(11.2)$ & 0.003 \\
\hline Waldeyer' string & $26(20.5)$ & $71(24.2)$ & 0.401 \\
\hline Bone & $9(7.1)$ & $12(4.1)$ & 0.196 \\
\hline Performance status 2-4 & 12(9.4) & $21 \otimes 7.2 \bigotimes$ & 0.425 \\
\hline B symptom & $28(22.0)$ & $76(26.0)$ & 0.396 \\
\hline Elevated LDH & $59 \rrbracket 46.5 \rrbracket$ & $135 \rrbracket 46.1 \rrbracket$ & 0.943 \\
\hline Stage $\otimes / \rrbracket$ & $72 \bigotimes 56.7 \rrbracket$ & $132 \rrbracket 45.1 \rrbracket$ & 0.028 \\
\hline Extra-nodal sites $\geq 2$ & $22 \bigotimes 17.3 \rrbracket$ & 49囚16.7》 & 0.880 \\
\hline IPI 3-5 & 24ه18.9® & $61 \rrbracket 20.8 \rrbracket$ & 0.653 \\
\hline Use of rituximab & $60 \rrbracket 47.2 \rrbracket$ & $143 \rrbracket 48.8 \rrbracket$ & 0.769 \\
\hline $\begin{array}{l}\text { Response to primary } \\
\text { chemotherapy }\end{array}$ & & & 0.300 \\
\hline Complete response & 78ه61.4』 & 196『66.9凶 & \\
\hline Partial response & 40囚31.5】 & 83囚28.3】 & \\
\hline Stable disease & $1(0.8)$ & $4(1.4)$ & \\
\hline Progressive disease & $7(5.5)$ & 10(3.4) & \\
\hline Not available & $1(0.8)$ & $0(0.0)$ & \\
\hline
\end{tabular}

IPI, International Prognostic Index; LDH, lactate dehydrogenase 


\begin{tabular}{|c|c|c|c|}
\hline Prognostic factor & $\begin{array}{l}\text { HBsAg-positive patients } \mathrm{n} / \mathrm{N} \\
(\%)\end{array}$ & $\begin{array}{l}\text { HBsAg-negative patients } \\
\mathrm{n} / \mathrm{N}(\%)\end{array}$ & $\begin{array}{l}P \\
\text { value }\end{array}$ \\
\hline $\begin{array}{l}\text { Cell of origin (non- } \\
\text { GCB) }\end{array}$ & $80 / 127(63.0)$ & $186 / 293(63.4)$ & 0.924 \\
\hline 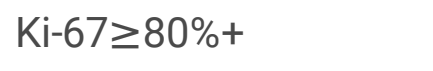 & $79 / 127(62.2 \rrbracket$ & 192/293(65.5区 & 0.513 \\
\hline $\mathrm{Bcl}-2+$ & 89/113(78.8) & 182/247(73.7) & 0.300 \\
\hline MYC+ & $28 / 57(49.1)$ & 78/117(66.7) & 0.026 \\
\hline Both MYC and $\mathrm{Bcl}-2+$ & $22 / 56(39.2)$ & $57 / 116(45.2)$ & 0.224 \\
\hline P53+ & $6 / 35(17.1)$ & $21 / 79(26.6)$ & 0.274 \\
\hline
\end{tabular}

Table 3: Treatment response in HBsAg-positive and negative patients with R-CHOP and CHOP regimen.

\begin{tabular}{|c|c|c|c|c|c|c|}
\hline \multirow[b]{2}{*}{ Treatment response } & \multicolumn{3}{|c|}{ HBsAg-positive patients } & \multicolumn{3}{|c|}{ HBsAg-negative patients } \\
\hline & $\begin{array}{l}\text { R-CHOP } \\
(n=60)\end{array}$ & $\begin{array}{l}\text { CHOP } \\
(n=66)\end{array}$ & $P$ Value & $\begin{array}{l}\text { R-CHOP } \\
(n=143)\end{array}$ & $\begin{array}{l}\text { CHOP } \\
(n=150)\end{array}$ & P Value \\
\hline Complete response & 42 & 36 & \multirow[t]{4}{*}{0.082} & 114 & 82 & \multirow[t]{4}{*}{0.001} \\
\hline Partial response & 15 & 25 & & 28 & 55 & \\
\hline Stable disease & 0 & 1 & & 1 & 3 & \\
\hline Progressive disease & 3 & 4 & & 0 & 10 & \\
\hline
\end{tabular}

Abbreviations: $\mathrm{CHOP}$, cyclophosphamide, doxorubicin, vincristine, and predinisone; R-CHOP, addition of rituximab to $\mathrm{CHOP}$.

Table 4 Treatment response between GCB subgroup and non-GCB subgroup in HBsAg-positive patients

\begin{tabular}{|c|c|c|c|c|c|c|}
\hline \multirow[b]{2}{*}{$\begin{array}{l}\text { Treatment } \\
\text { response }\end{array}$} & \multicolumn{3}{|c|}{ HBsAg-positive patients } & \multicolumn{3}{|c|}{ HBsAg-negative patients } \\
\hline & $\begin{array}{l}\text { GCB } \\
(n=47)\end{array}$ & $\begin{array}{l}\text { non-GCB } \\
(n=79)\end{array}$ & $\begin{array}{l}\mathrm{P} \\
\text { Value }\end{array}$ & $\begin{array}{l}\text { GCB } \\
(n=107)\end{array}$ & $\begin{array}{l}\text { non-GCB } \\
(n=186)\end{array}$ & $\begin{array}{l}\mathrm{P} \\
\text { Value }\end{array}$ \\
\hline Complete response & 42 & 46 & \multirow[t]{4}{*}{0.252} & 73 & 123 & \multirow[t]{4}{*}{0.718} \\
\hline Partial response & 15 & 27 & & 29 & 54 & \\
\hline Stable disease & 0 & 1 & & 2 & 2 & \\
\hline $\begin{array}{l}\text { Progressive } \\
\text { disease }\end{array}$ & 3 & 5 & & 3 & 7 & \\
\hline
\end{tabular}




\begin{tabular}{|c|c|c|c|c|}
\hline \multirow[t]{2}{*}{ Characteristics } & \multicolumn{2}{|c|}{ HBsAg-positive DLBCL patients } & \multicolumn{2}{|c|}{ HBsAg- negative DLBCL patients } \\
\hline & $N($ total=127) & Log-rank P value & N (total=293) & Log-rank $\mathrm{P}$ value \\
\hline Gender & & 0.5748 & & 0.6699 \\
\hline Male & 79 & & 158 & \\
\hline Female & 48 & & 135 & \\
\hline Age/year & & 0.0377 & & $₫ 0.0001$ \\
\hline$\nabla 60$ & 22 & & 97 & \\
\hline$\leq 60$ & 105 & & 196 & \\
\hline Clinical staging & & 0.0002 & & $\bowtie 0.0001$ \\
\hline I & 18 & & 48 & \\
\hline II & 37 & & 113 & \\
\hline III & 34 & & 44 & \\
\hline IV & 38 & & 88 & \\
\hline B-symptoms & & 0.0003 & & 0.697 \\
\hline Yes & 28 & & 76 & \\
\hline No & 99 & & 217 & \\
\hline Elevated LDH & (4 unkown) & 0.0487 & & $\bowtie 0.0001$ \\
\hline Yes & 67 & & 135 & \\
\hline No & 56 & & 158 & \\
\hline Treated with rituximab & & 0.0152 & & 0.002 \\
\hline Yes & 60 & & 143 & \\
\hline No & 67 & & 150 & \\
\hline Spleen involvement & & 0.034 & & 0.002 \\
\hline Yes & 28 & & 19 & \\
\hline No & 99 & & 274 & \\
\hline Bcl-2ðMyc Positive & (71unkown) & 0.048 & (177unkown) & 0.037 \\
\hline Yes & 34 & & 57 & \\
\hline No & 22 & & 59 & \\
\hline $\begin{array}{l}\text { roll af nrinin } \\
\text { ading [MathJax]/jax/output/Co }\end{array}$ & nonHTML/jax.js & 0.124 & & 0.103 \\
\hline
\end{tabular}




\begin{tabular}{|c|c|c|c|c|}
\hline GCB & 47 & & 107 & \\
\hline non-GCB & 80 & & 186 & \\
\hline HBV DNA copies & (7unkown) & 0.536 & - & - \\
\hline ه1000 copies/ml & 51 & & & \\
\hline ه1000 copies/ml & 69 & & & \\
\hline HBeAg & (7unkown) & 0.534 & - & - \\
\hline Yes & 25 & & & \\
\hline No & 95 & & & \\
\hline
\end{tabular}

Table 6: Multivariate Cox proportional hazards model for analysis of survival in HBsAg-positive DLBCL patients 


\begin{tabular}{|c|c|c|c|c|}
\hline \multirow[t]{2}{*}{ Characteristics } & \multirow[t]{2}{*}{$P$ value } & \multirow[t]{2}{*}{ HR } & \multicolumn{2}{|l|}{$95 \% \mathrm{Cl}$} \\
\hline & & & Lower & Upper \\
\hline Age/year & 0.319 & & & \\
\hline$₫ 60$ & & 1.940 & 0.528 & 7.132 \\
\hline$\leq 60$ & & 1 & - & - \\
\hline Clinical staging & 0.532 & & & \\
\hline $\mathrm{I} / \mathrm{II}$ & & 1 & - & - \\
\hline III/IV & & 1.500 & 0.421 & 5.337 \\
\hline B-symtoms & 0.287 & & & \\
\hline Yes & & 1.969 & 0.565 & 6.860 \\
\hline No & & 1 & - & - \\
\hline Elevated LDH & 0.598 & & & \\
\hline Yes & & 1.345 & 0.448 & 4.037 \\
\hline No & & 1 & - & - \\
\hline Treated with rituximab & 0.023 & & & \\
\hline Yes & & 0.294 & 0.102 & 0.843 \\
\hline No & & 1 & - & - \\
\hline Spleen involvement & 0.007 & & & \\
\hline Yes & & 3.725 & 1.444 & 9.614 \\
\hline No & & 1 & - & - \\
\hline Bcl-2邓Myc Positive & 0.090 & & & \\
\hline Yes & & 2.270 & 0.879 & 5.862 \\
\hline No & & 1 & - & - \\
\hline
\end{tabular}

Figures 


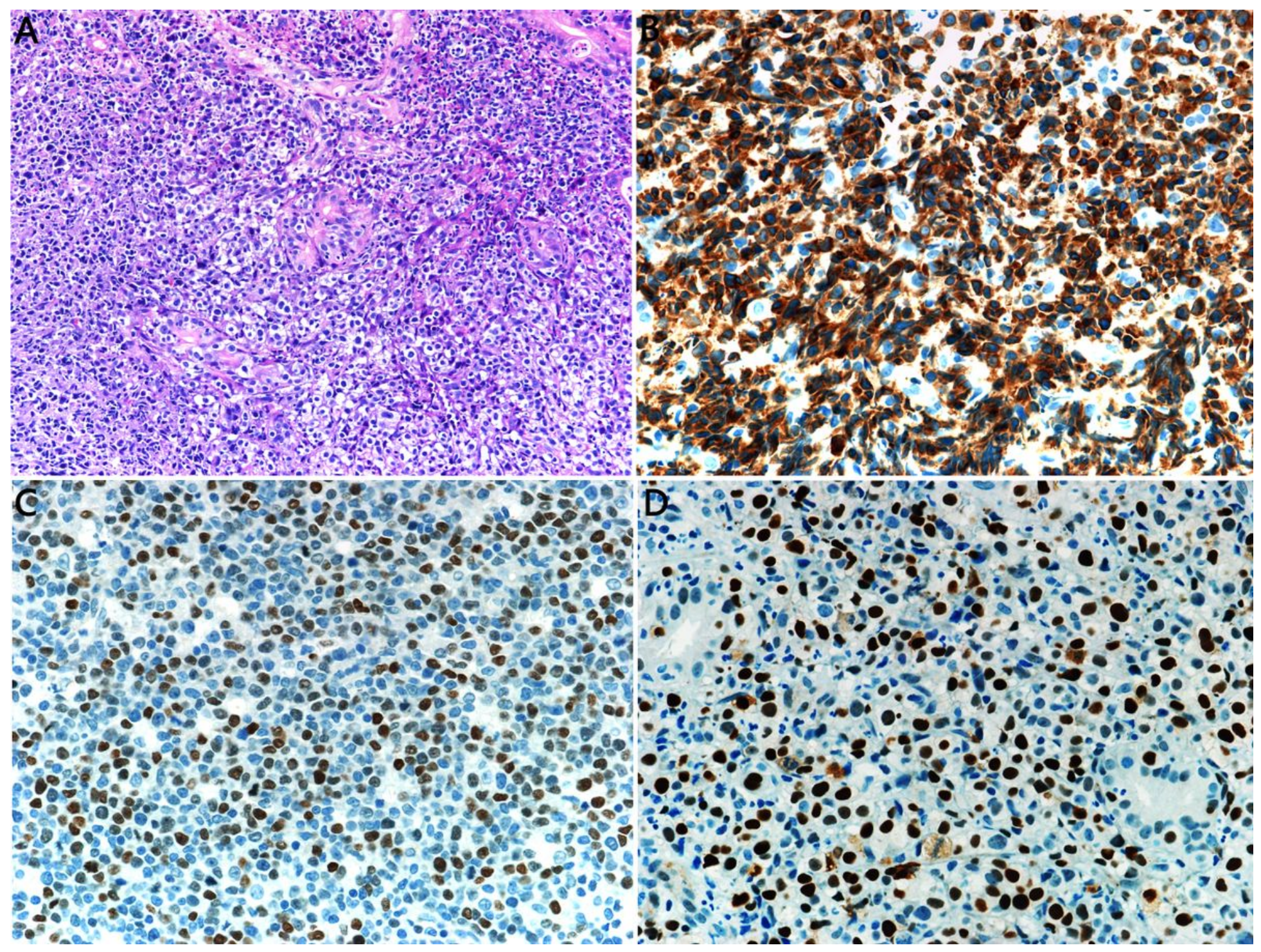

Figure 1

Immunohistochemical staining of diffuse large B-cell lymphoma (DLBCL) tissues. A. Hematoxylin and eosin staining of DLBCL ( $\times 400)$. B. BCL-2 was positively expressed in the nuclei of DLBCL cells $(\times 400)$. C. c-MYC was positively expressed in the nuclei of DLBCL cells $(\times 400)$. D. p53 was positively expressed in the nuclei of DLBCL cells $(\times 400)$. 


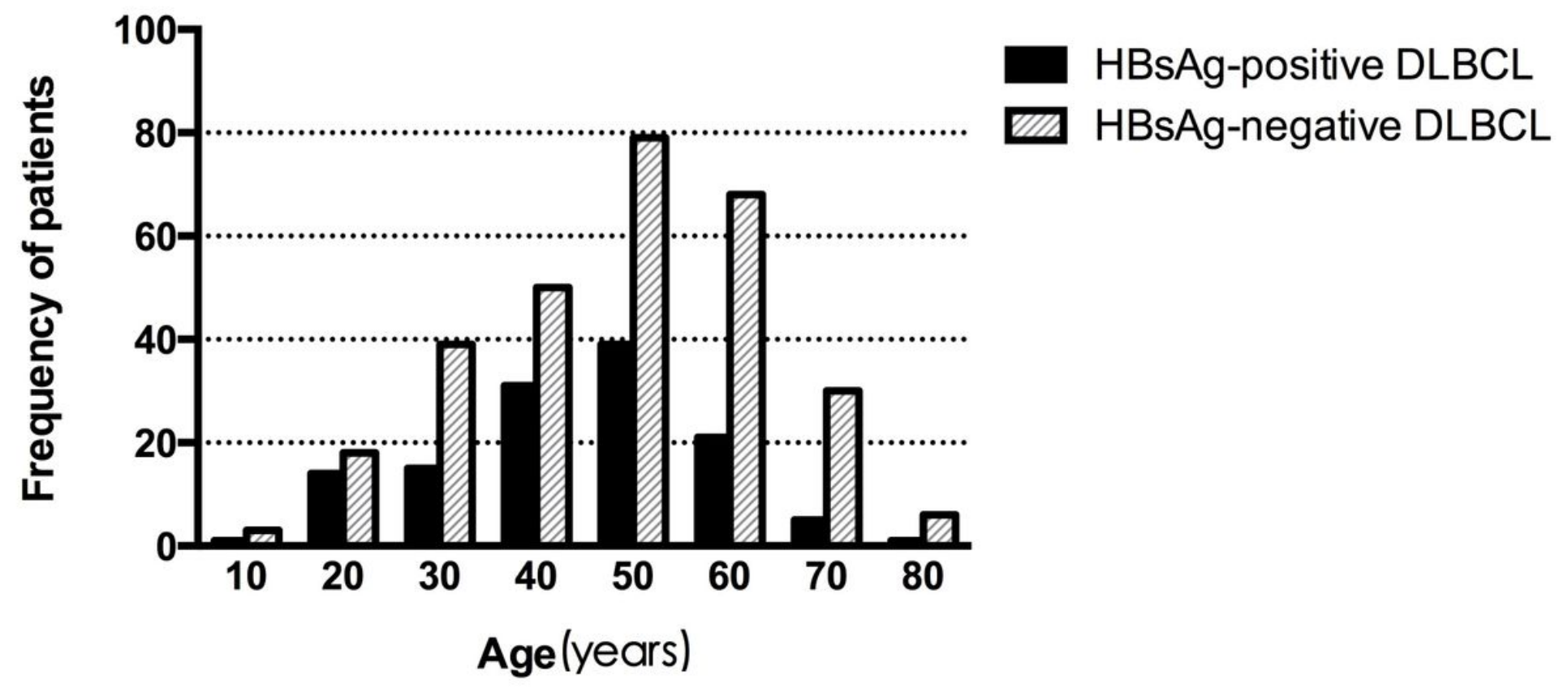

Figure 2

Age distribution of diffuse large B-cell lymphoma patients in HBsAg-positive and -negative groups.
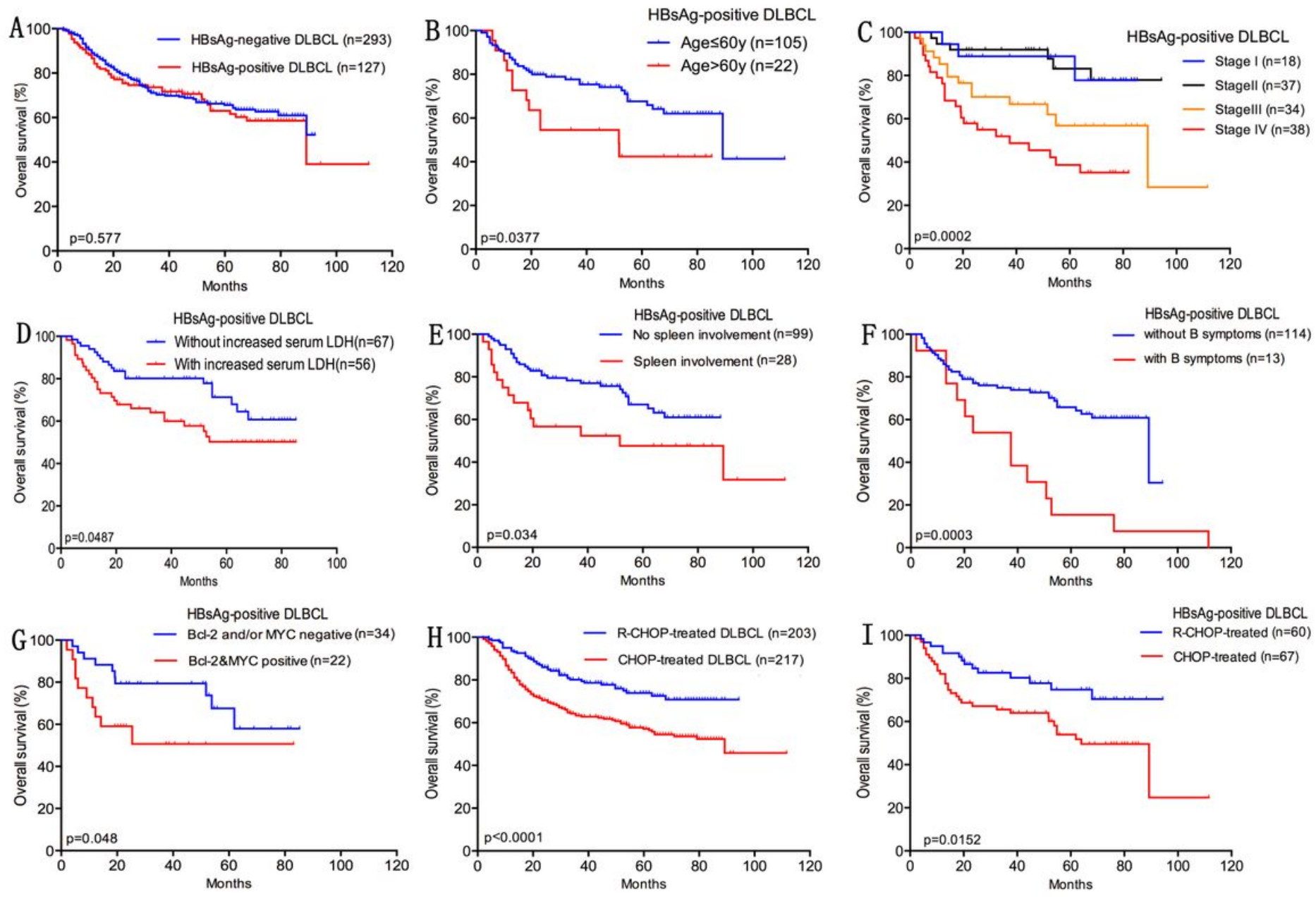


\section{Figure 3}

Survival analysis of HBsAg-positive diffuse large B-cell lymphoma patients. A. Overall survival (OS) of HBsAg-positive and -negative DLBCL patients. B. OS of HBsAg-positive DLBCL patients of more than 60 years old and less than 60 years old. C. OS of clinical staging in HBsAg-positive DLBCL patients. D. OS of HBsAg-positive DLBCL patients with and without elevated LDH. E. OS of HBsAg-positive DLBCL patients with and without spleen involvement. F. OS of HBsAg-positive DLBCL patients with and without B symptoms. G. OS of HBsAg-positive DLBCL patients with and without coexpression of BCL2 and MYC. H. OS of DLBCL patients treated with R-CHOP or CHOP regimens. I. OS of HBsAg-positive DLBCL patients treated with $\mathrm{R}-\mathrm{CHOP}$ or $\mathrm{CHOP}$ regimens.

\section{Supplementary Files}

This is a list of supplementary files associated with this preprint. Click to download.

- SupplementaryMaterials.docx 